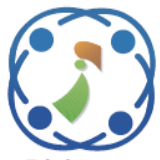

\title{
Design of Optimal Backstepping Control for a Wind Power Plant System Using the Adaptive Weighted Particle Swarm Optimization
}

\author{
Elmostafa Chetouani ${ }^{1 *}$ \\ Youssef Errami ${ }^{1}$ \\ Abdellatif Obbadi ${ }^{1}$ \\ Smail Sahnoun ${ }^{1}$ \\ ${ }^{1}$ Laboratory: Electronics, Instrumentation and Energy - Team: Exploitation and Processing of Renewable Energy \\ - Department of Physics - Faculty of Sciences - University of Chouaib Doukkali, El Jadida, Morocco \\ * Corresponding author's Email: chetouani.m@ucd.ac.ma
}

\begin{abstract}
This paper proposes a nonlinear optimal Backstepping method for controlling the doubly-fed induction generator used in wind energy conversion and obtainingmaximum power. The grid is connected directly to the stator. The rotor, on the other hand, is connected to the grid via two bidirectional converters. This work aims to regulate active and reactive power while maintaining a unit power factor using the proposed controller. The Lyapunov function guarantees the stability of the system. The most challenging aspect of Backstepping is determining the best positive constants, which are critical to the system performance. This process becomes more complex, especially when the generator parameters are uncertain or when the wind profile varies. As a result, optimizing the gains is an essential aspect of the controller design. The particle swarm optimization method is suggested for determining the optimum Backstepping constants. The performance and robustness of the proposed method are investigated and compared to the Conventional Backstepping and the Proportional-Integral Control strategies of a $5 \mathrm{MW}$ wind power plant system under parameter variations and quickly changing wind speed profiles. Matlab/Simulink makes it possible to get results. The advised methodology ensures the tracking system's robust stability and reduces the response time to $1.8(\mathrm{~m} \mathrm{~s})$. Furthermore, it guarantees a negligible static error.
\end{abstract}

Keywords: Backstepping control, DFIG, Particle swarm optimization, PI controller, Wind power plant system.

\section{Introduction}

Our daily lives have become increasingly reliant on electrical energy. As a result, power plants must produce it continually while also meeting environmental criteria. The best solution is to migrate to renewable energy sources such as wind or solar energy. Wind energy is more cost-competitive than solar energy due to its year-round availability, both offshore and onshore. During the winter, the latter presents a significant challenge for electric production. Because of the advancement of technology, wind energy now holds a key position in the industry, with competitive development potential.

The wound-rotor induction generator is becoming widely used in Wind Energy Conversion Systems (WECS). This is due to a variety of factors, including its ability to operate at low and high speeds, its ability to control power with a partial sized converter in the rotor, decreasing power losses and costs, lowering efforts on mechanical parts, noise reduction, power control, and a controllable power factor [1]. As illustrated in Fig. 1, the Doubly Fed Induction Generator (DFIG) stator is connected directly to the grid, while the rotor is connected to the electrical network via two bidirectional converters. The rotor side converter is used to regulate the Unit Power Factor (UPF) and control the power exchanged with the grid. The grid side converter, on the other hand, is used to keep the bus voltage constant [2]. The mathematical equations of the induction machine model are complex and nonlinear. Because the input variables are strongly coupled, regulating active and reactive power independently is a difficult process [3]. In order to achieve high performance and convert a nonlinear system model into a linear model, numerous control strategies have been used to operate the DFIG 
intended for the wind chain. These control techniques are generally based on the Field-Oriented Control (FOC) principle. Feedback Linearization is one of the strategies used to linearize the non-linear system [4]. This method of controlling a nonlinear multi-variable doubly-fed induction generator while considering magnetic saturation was proposed by the authors. The results show that nonlinear feedback is still susceptible to parameter change and provides an unsatisfactory result. To improve performance, feedback linearization is used with additional methods such as sliding mode or Backstepping. The Sliding Mode Controller (SMC) for a WEC system based on feedback linearization was investigated in [5]. Moreover, in [3], the SMC and non-adaptive Backstepping control were established as two non-linear controllers, allowing system stability analysis without solving the mathematical equations analytically. Similarly, rotor field-oriented control and adaptive Backstepping were compared and applied to a doubly-fed inductor motor in [6]. The robustness of the suggested control is tested by changing the motor parameter. Additionally, in [7], a comparison study of nonlinear SMC and Backstepping Control (BSC) is proposed for managing rotor and grid side converters. The authors demonstrated that the BSC provides robustness and linearization of the WECS based on the DFIG when compared to the SMC. Y. Djeriri 2020 [8] has also developed a Backstepping approach for commanding the DFIG's rotor side converter in order to pilot the stator powers. Variation of the DFIG settings at a fixed wind speed is used to verify the robustness. Furthermore, the PI controller has been replaced in [9] by a Backstepping controller, in which parameter values are manually and arbitrarily selected. The obtained findings demonstrate that the proposed methodology ensures appropriate reference regulation and system stability. In [10], a Backstepping controller for the DFIG trained by the wind turbine is developed. The authors compared the proposed approach to the conventional Proportional-Integral (PI) controller and demonstrated that the performances are significantly improved. Because of its capacity to provide a stronger stabilization command based on the Lyapunov function, it can minimize plant uncertainties, and it has been utilized to solve the trajectory tracking problem of systems [11], the Backstepping approach has attracted a lot of interest.

The drawback related to conventional Backstepping is that it is not robust against parameter machine modification, as demonstrated by the above-mentioned works. Furthermore, the appropriate choice of positive constants remains the most difficult task. However, manually setting the constants takes a long time, and the parameters should be readjusted if the wind profile changes. Many researchers have recently advocated optimization strategies for finding the best positive constants in the Lyapunov function. Neural Network Controller (NNC), Fuzzy Logic Controller (FLC), Genetic Algorithm (GA), Rooted Tree Optimization (RTO), Artificial Bee Colony (ABC), and Particle Swarm Optimization (PSO) are some examples of algorithms. The ABC approach is introduced in [12] to track the Maximum Power Point Tracking (MPPT) under different wind speeds. They also used Particle Swarm Optimization to choose the best value of the Backstepping invariants to generate the pulse width modulation for the rotor side converter, allowing for better stator power tracking. To regulate the WEC system's powers, a Backstepping controller based on DFIG is presented in [13]. The Genetic Algorithm (GA) is advised to specify the optimal Backstepping parameters [13]. The GA is still quite difficult to implement. The NNC is also used to determine the Backstepping constants for a DFIG in [14]. Significant oscillations can be noticed in the transient regime, according to the simulation results. The Particle Swarm Optimization (PSO) method was used to find the best Backstepping parameter values. This optimization methodology has recently demonstrated various advantages, including accurately selecting Backstepping settings, decreasing calculation time, maintaining great precision, and being able to be implemented in a low-cost microcontroller [15]. Influence and social learning, high outcomes for nonlinear and continuous problems, and adaptability for single and multi-objective problems are also essential properties of particle swarm optimization [16]. The Matlab/Simulink platform is used to model and simulate a wound rotor induction generator of 5 MW in this paper. The optimum Backstepping control is used to control the Rotor Side Converter (RSC) and the Grid Side Converter (GSC). The main contribution is to use the meta-heuristic Particle Swarm Optimization to find the best values for Backstepping multi parameters (PSOBS) for tracking maximum power point, controlling injected powers, regulating the power factor to one, and keeping the DC-link voltage constant. The suggested optimization methodology is applied to wind energy systems under variable wind speed conditions, and simulation results are shown and analyzed. 


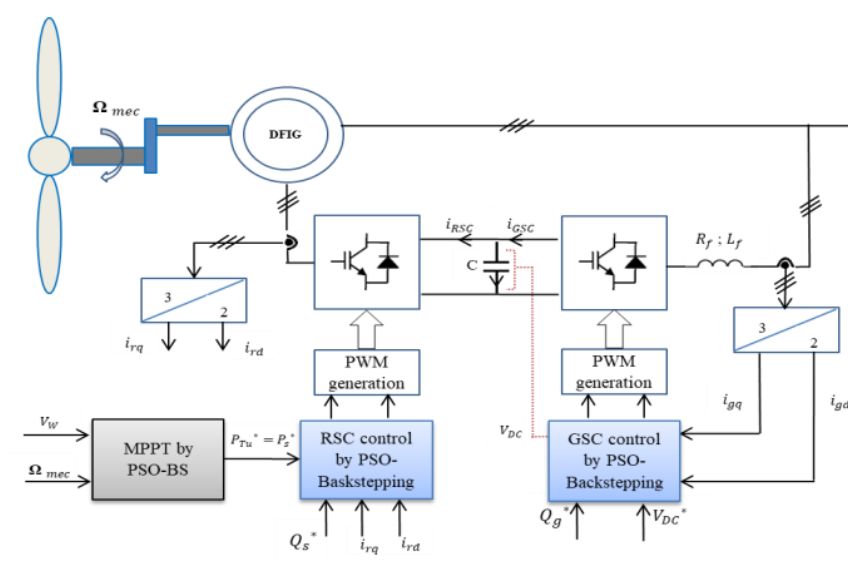

Figure. 1 Scheme of the wind power plant system

There are six sections to the paper. Starting with an introduction in Section 1, Section 2 describes a modeling and indirect field-oriented control of a wind power plant system based on a DFIG using conventional PI controllers. The Backstepping theorem is highlighted in Section 3 to build the MPPT strategy, control the active and reactive powers, and regulate the DC-link voltage. The adaptive weighted particle swarm optimization methodology is proposed in Section 4 to determine the Backstepping constants optimally. In Section 5, the simulation results and the robustness of the suggested method are interpreted and examined. The conclusion is offered in Sect. 6.

\section{Wind energy conversion system modeling}

\subsection{Wind turbine modeling}

The produced aerodynamic power of the wind turbine is provided by [17]:

$$
P_{\text {mech }}=P_{T u}=\frac{1}{2} \cdot C_{P}(\lambda, \beta) \cdot \rho \cdot \pi \cdot R^{2} \cdot V_{w}{ }^{3}
$$

Where $\rho$ is the air density $\left(\mathrm{kg} / \mathrm{m}^{3}\right), \mathrm{V}_{\mathrm{w}}$ is the wind speed (in $\mathrm{m} / \mathrm{s}$ ), $\mathrm{R}$ is the blade radius $(\mathrm{m})$, and $\mathrm{C}_{P}$ is the performance coefficient of the turbine. The latter is expressed as a function of the wind turbine pitch angle $(\beta)$ and the Tip Speed Ratio (TSR) $(\lambda)$ by the following equation [18]:

$$
\begin{aligned}
& C_{P}(\lambda, \beta)=[0.5-0.0167 .(\beta- \\
& 2)] . \sin \left(\frac{\pi(\lambda+0.1)}{18.5-0.3 \cdot(\beta-2)}\right)-0.00184 .(\lambda-3) \cdot(\beta-2)
\end{aligned}
$$

The TSR $\lambda$ equation is given as follows [18]:

$$
\lambda=\frac{R \cdot \Omega_{T u}}{V}
$$

The mechanical torque $\left(\mathrm{T}_{\mathrm{Tu}}\right)$ is written as below:

$$
T_{T u}=\frac{P_{m e c h}}{\Omega_{T u}}
$$

The mechanical speed is given by [18]:

$$
J_{t o t} \cdot \frac{d \Omega_{m e c}}{d t}+f . \Omega_{m e c}=T_{g}-T_{e m}
$$

Where $T_{g}=\frac{T_{T u}}{G_{B}}$ and $G_{B}=\frac{\Omega_{m e c}}{\Omega_{T u}}$

Where $\mathrm{J}_{\text {tot }}$ is the overall inertia of WECS, $\mathrm{T}_{\mathrm{Tu}}$ is the turbine torque, $\mathrm{T}_{\mathrm{Tem}}$ is the DFIG's electromagnetic torque, $\mathrm{f}$ is the overall viscous coefficient of friction, $\Omega_{\text {mec }}$ is the mechanical speed of the gearbox shaft $\left.(\operatorname{rad~s})^{-1}\right)$ that will drive the DFIG, and $G_{B}$ is the gearbox multiplier.

\subsection{Doubly-fed induction generator modeling}

The electrical equations of the DFIG are complex and nonlinear. Thanks to the Park transform, the electrical model can be simplified. These equations are $[3,8]$ :

$$
\begin{gathered}
\left\{\begin{array}{l}
V_{s d}=R_{s} i_{s d}+\frac{d \varphi_{s d}}{d t}-\omega_{s} \varphi_{s q} \\
V_{s q}=R_{s} i_{s q}+\frac{d \varphi_{s q}}{d t}+\omega_{s} \varphi_{s d} \\
V_{r d}=R_{r} i_{r d}+\frac{d \varphi_{r d}}{d t}-\omega_{r} \varphi_{r q} \\
V_{r q}=R_{r} i_{r q}+\frac{d \varphi_{r q}}{d t}+\omega_{r} \varphi_{r d}
\end{array}\right. \\
\left\{\begin{array}{l}
\varphi_{s d}=L_{s} i_{s d}+M \cdot i_{r d} \\
\varphi_{s q}=L_{s} \cdot i_{s q}+M \cdot i_{r q} \\
\varphi_{r d}=L_{r} \cdot i_{r d}+M \cdot i_{s d} \\
\varphi_{r q}=L_{r} \cdot i_{r q}+M \cdot i_{s q}
\end{array}\right.
\end{gathered}
$$

Where $V_{s}$ and $V_{r}$ are the stator and rotor voltage, $i_{s}$ and $i_{r}$ are the stator and the rotor current, $\varphi_{s}$ and $\varphi_{r}$ are the stator and the rotor flux linkages, $R_{s}$ and $R_{r}$ are the stator and the rotor resistances.

The stator and rotor pulse currents $\left(\omega_{\mathrm{s}}\right.$ and $\left.\omega_{\mathrm{r}}\right)$ are connected with the following expression:

$$
\omega_{r}=\omega_{s}-p . \Omega_{m e c}=g . \omega_{s}
$$

The number of DFIG pole pairs is $\mathrm{p}$, and the slip is $\mathrm{g}$. The stator, rotor, and magnetizing inductances are Ls, Lr, and M, respectively. The electromagnetic torque can be given by [19]:

$$
T_{e m}=-p \cdot \frac{M}{L_{s}}\left(i_{r q} \cdot \varphi_{s d}-i_{r d} \cdot \varphi_{s q}\right)
$$


The active and reactive powers of the stator and rotor are represented as follows [3, 19]:

$$
\begin{gathered}
P_{s}=V_{s d} \cdot i_{s d}+V_{s q} \cdot i_{s q} \\
Q_{s}=V_{s d} \cdot i_{s d}-V_{s d} \cdot i_{s q}
\end{gathered}
$$

\subsection{Maximum power point tracking strategy}

Controlling electromechanical torque generated by a PI controller is used to regulate the DFIG's rotation speed. The electromagnetic torque $T_{e m}$ developed by the DFIG is equal to its optimal value $\mathrm{T}_{\text {em-opt. }}$ The latter is imposed by the command [20]:

$$
T_{\text {em }}=T_{\text {em-opt }}
$$

The optimal electromagnetic torque $\mathrm{T}_{\text {em-opt }}$ is given as:

$$
\begin{aligned}
& T_{\text {em-opt }}=\left[K_{\text {pmppt }}+K_{\text {imppt }} \cdot \frac{1}{s}\right] \cdot\left[\Omega_{\text {mec-opt }}-\right. \\
& \left.\Omega_{\text {mec }}\right]
\end{aligned}
$$

The gains of the PI controller are expressions are given as:

$$
K_{\text {imppt }}=\frac{1}{\tau \cdot f} ; K_{p m p p t}=\frac{-K_{\text {imppt }} \cdot J_{t o t}}{f}
$$

\section{Backstepping control of the DFIG}

\subsection{Principle of backstepping control}

Backstepping is a nonlinear technique capable to break down a complex system into a sequence of sub-problems on lower-order systems. The basic idea of this approach is to design a controller for a system recursively by considering some of the state variables as "Virtual Controls" and designing for them intermediate control laws with the Control Lyapunov Function [21]. Starting with the definition of a virtual control state and then forcing it to become a stabilizing function. Consequently, by designing the related control input based on the Lyapunov stability, the error variable can be stabilized [22].

\subsection{MPPT strategy backstepping controller}

The Backstepping methodology is utilized to construct the control based on Eq. (5), which is the equation for the dynamic rotation speed of the DFIG. In the first step, the error variable is declared as follows:

$$
\varepsilon_{\Omega}=\Omega_{m e c}^{*}-\Omega_{m e c}
$$

The derivative of DFIG rotation speed is defined as:

$$
\frac{d \Omega_{m e c}}{d t}=\frac{1}{J_{t o t}} \cdot\left(T_{g}-T_{e m}-f \cdot \Omega_{m e c}\right)
$$

The derivative of the error presented is given by:

$$
\dot{\varepsilon}_{\Omega}=\dot{\Omega}_{m e c}^{*}-\dot{\Omega}_{m e c}
$$

By replacing Eq. (17) in Eq. (18) we obtain:

$$
\dot{\varepsilon}_{\Omega}=\dot{\Omega}_{m e c}-\frac{1}{J_{t o t}} \cdot\left(T_{g}-T_{e m}-f . \Omega_{m e c}\right)
$$

Choosing $\mathrm{L}_{\text {f-mppt }}$ as a Lyapunov function [17]:

$$
L_{f-m p p t}=\frac{1}{2} \cdot \varepsilon_{\Omega}^{2}
$$

Computing the derivative of $L_{f-m p p t}$ as:

$$
\dot{L}_{f-m p p t}=\varepsilon_{\Omega} \cdot \dot{\varepsilon}_{\Omega}=\varepsilon_{\Omega} \cdot\left(\dot{\Omega}_{m e c}^{*}-\dot{\Omega}_{m e c}\right)
$$

Equation (21) can be written as:

$$
\begin{aligned}
& \dot{L}_{f-m p p t}=\varepsilon_{\Omega} \cdot\left[\dot{\Omega}_{m e c}^{*}-\frac{1}{J_{t o t}} \cdot\left(T_{g}-T_{e m}-\right.\right. \\
& \left.\left.f . \Omega_{m e c}\right)\right]
\end{aligned}
$$

To analyze the stability of this system, we define the Stabilizing function of Lyapunov, which is called virtual control as [17]:

$$
\dot{L}_{f-m p p t}=-C_{m p p t} \cdot \varepsilon_{\Omega}^{2}
$$

Where: $\mathrm{C}_{\mathrm{mppt}}$ is a positive constant. The virtual command $\mathrm{T}_{\mathrm{em}}$ can be defined by:

$$
T_{e m}^{*}=-J_{t o t}\left(\dot{\Omega}_{m e c}^{*}+C_{m p p t} \cdot \varepsilon\right)+T_{g}-f \cdot \Omega_{m e c}
$$

\subsection{Rotor side converter controller design}

The virtual control should be designed based on the rotor currents. The derivation of the rotor currents equations can be deduced as follows: 


$$
\left\{\begin{array}{l}
\frac{d i_{r d}}{d t}=\frac{1}{a}\left(V_{r d}-R_{r} \cdot i_{r d}+b \cdot i_{r q}\right) \\
\frac{d i_{r q}}{d t}=\frac{1}{a}\left(V_{r q}-R_{r} \cdot i_{r q}-b \cdot i_{r q}-c\right)
\end{array}\right.
$$

Where: $a=L_{r} \cdot\left(1-\frac{M^{2}}{L_{r} \cdot L_{s}}\right) ; \quad b=g \cdot \omega_{s} \cdot L_{r}(1-$ $\left.\frac{M^{2}}{L_{r} \cdot L_{S}}\right) ; \quad c=\frac{M \cdot V_{S} \cdot g}{L_{S}}$

Calculating the derivative of the rotor currents errors:

$$
\frac{d \varepsilon_{r s c 1}}{d t}=\frac{d i_{r q}^{*}}{d t}-\frac{d i_{r q}}{d t} \text { and } \frac{d \varepsilon_{r s c 2}}{d t}=\frac{d i_{r d}^{*}}{d t}-\frac{d i_{r d}}{d t}
$$

Replacing the time derivative of currents in Eq. (26), we obtain:

$$
\begin{aligned}
& \frac{d \varepsilon_{r s c 1}}{d t}=\frac{d i_{r q}^{*}}{d t}-\frac{1}{a}\left(V_{r q}-R_{r} \cdot i_{r q}-b \cdot i_{r q}-c\right) \\
& \frac{d \varepsilon_{r s c 2}}{d t}=\frac{d i_{r d}^{*}}{d t}-\frac{1}{a}\left(V_{r d}-R_{r} \cdot i_{r d}+b \cdot i_{r q}\right)
\end{aligned}
$$

The Lyapunov candidate function is defined, in a second step, as follows:

$$
L_{f-r s c}=\frac{\varepsilon_{r s c 1}^{2}}{2}+\frac{\varepsilon_{r s c 2}^{2}}{2}
$$

The derivation of Lyapunov function is:

$$
\dot{L}_{f-r s c}=\varepsilon_{r s c 1} \cdot \dot{\varepsilon}_{r s c 1}+\varepsilon_{r s c 2} \cdot \dot{\varepsilon}_{r s c 2}
$$

The Lyapunov derivative can be calculated by substituting the error derivation in Eq. (30):

$$
\begin{aligned}
& \dot{L}_{f-r s c}=\varepsilon_{r s c 1} \cdot\left[\frac{d i_{r q}^{*}}{d t}-\frac{1}{a}\left(V_{r q}-R_{r} i_{r q}-b \cdot i_{r q}-\right.\right. \\
& c)]+\varepsilon_{r s c 2} \cdot\left[\frac{d i_{r d}^{*}}{d t}-\frac{1}{a}\left(V_{r d}-R_{r} i_{r d}+b \cdot i_{r q}\right)\right]
\end{aligned}
$$

According to the Lyapunov function, the derivation of $\mathrm{L}_{\mathrm{f}-\mathrm{rsc}}$ must be negative to ensure system stability and it is as follows:

$$
\dot{L}_{f-r s c}=-C_{r s c 1} \cdot \varepsilon_{r s c 1}^{2}-C_{r s c 2} \cdot \varepsilon_{r s c 2}^{2}
$$

The constants $\mathrm{C}_{\mathrm{rsc} 1}$ and $\mathrm{C}_{\mathrm{rsc} 2}$ are both positive. We get the following result by equating the two Eqs. (31) and (32):

$\frac{d i_{r q}^{*}}{d t}-\frac{1}{a}\left(V_{r q}-R_{r} i_{r q}-b \cdot i_{r q}-c\right)=-C_{r s c 1} \cdot \varepsilon_{r s c 1}$ $\frac{d i_{r d}^{*}}{d t}-\frac{1}{a}\left(V_{r d}-R_{r} i_{r d}+b \cdot i_{r q}\right)=-C_{r s c 2} \cdot \varepsilon_{r s c 2}$

Therefore, the virtual command $V_{r q}^{*}$ and $V_{r d}^{*}$ are deduced directly as follows:

$$
\begin{aligned}
V_{r q}^{*} & =a \cdot\left[\frac{d i_{r q}^{*}}{d t}+\frac{R_{r}}{a} i_{r q}+\frac{b}{a} \cdot i_{r d}+\frac{c}{a}+C_{r s c 1} \cdot \varepsilon_{r s c 1}\right] \\
V_{r d}^{*} & =a \cdot\left[\frac{d i_{r d}^{*}}{d t}+\frac{R_{r}}{a} i_{r d}-\frac{b}{a} \cdot i_{r q}+C_{r s c 2} \cdot \varepsilon_{r s c 2}\right]
\end{aligned}
$$

\subsection{Grid side converter controller design}

The Backstepping technique is used to keep the DC link voltage constant and to generate a current reference for regulating the powers. The difference in DC-link voltages is described as:

$$
\varepsilon_{d c}=V_{d c}^{*}-V_{d c}
$$

The derivative of the error is given by:

$$
\dot{\varepsilon}_{d c}=\dot{V}_{d c}^{*}-\dot{V}_{d c}
$$

Selecting the first Lyapunov function for the DC bus voltage error:

$$
L_{f-d c}=\frac{\varepsilon_{d c}^{2}}{2}
$$

The derivative of Eq. (39) gives:

$$
\dot{L}_{f-d c}=\varepsilon_{d c} \cdot \dot{\varepsilon}_{d c}=\varepsilon_{d c}\left(\dot{V}_{d c}^{*}-\frac{i_{c}}{c}\right)
$$

This can be rewritten satisfying $\dot{\mathrm{L}}_{\mathrm{f}-\mathrm{dc}}<0$ as follows:

$$
\dot{L}_{f-d c}=-C_{d c} \cdot \varepsilon_{d c}^{2}
$$

Where $\mathrm{C}_{\mathrm{dc}}$ is a positive parameter. From Eqs. (38) and (40), we can write:

$$
\dot{V}_{d c}^{*}-\frac{i_{c}}{c}=-C_{d c} \cdot \varepsilon_{d c}
$$

Eq. (42) allows the synthesis of the DC link current reference $\left(i_{c}^{*}\right)$, such as:

$$
i_{c}^{*}=C \cdot\left(\dot{V}_{d c}^{*}+C_{d c} \cdot \varepsilon_{d c}\right)
$$

On the other hand, we have: 


$$
i_{c}^{*}=\frac{P_{d c}^{*}}{V_{d c}} \quad \text { and } \quad i_{g q}^{*}=\frac{P_{g s c}^{*}}{V_{g}}
$$

Therefore, the quadrature grid current reference can be expressed as a function of the DC-link voltage as:

$$
i_{g q}^{*}=\frac{C \cdot V_{d c} \cdot\left(\dot{V}_{d c}^{*}+C_{d c} \cdot \varepsilon_{d c}\right)+P_{r s c}}{V_{g}}
$$

$\mathrm{P}_{\text {rsc }}$ denotes the rotor's power. The expressions of the time derivative of grid currents are:

$$
\begin{aligned}
\frac{d i_{g d}}{d t} & =\frac{1}{L_{f}}\left(-V_{g d}-R_{f} i_{g d}+\omega_{s} \cdot L_{f} \cdot i_{g q}\right) \\
\frac{d i_{g q}}{d t} & =\frac{1}{L_{f}}\left(-V_{g q}-R_{f} i_{g q}-\omega_{s} \cdot L_{f} \cdot i_{g d}+V_{g}\right)
\end{aligned}
$$

The derivative of the rotor currents errors is given by:

$$
\frac{d \varepsilon_{g s c 1}}{d t}=\frac{d i_{g q}^{*}}{d t}-\frac{d i_{g q}}{d t} \text { and } \frac{d \varepsilon_{g s c 2}}{d t}=\frac{d i_{g d}^{*}}{d t}-\frac{d i_{g d}}{d t}
$$

The errors derivative becomes as follows:

$\frac{d \varepsilon_{g s c 1}}{d t}=\frac{d i_{g q}^{*}}{d t}-\frac{1}{L_{f}}\left(-V_{g q}-R_{f} i_{g q}-\omega_{s} . L_{f} \cdot i_{g d}+\right.$

$\left.V_{g}\right)$

$\frac{d \varepsilon_{g s c 2}}{d t}=\frac{d i_{g d}^{*}}{d t}-\frac{1}{L_{f}}\left(-V_{g d}-R_{f} i_{g d}+\omega_{s} \cdot L_{f} \cdot i_{g q}\right)$

Lyapunov function is defined by:

$L_{f-g s c}=\frac{\varepsilon_{g s c 1}^{2}}{2}+\frac{\varepsilon_{g s c 2}^{2}}{2}$

The derivation of Lyapunov function is expressed by:

$$
\begin{aligned}
& \dot{L}_{f-g s c}=\varepsilon_{g s c 1} \cdot \dot{\varepsilon}_{g s c 1}+\varepsilon_{g s c 2} \cdot \dot{\varepsilon}_{g s c 2} \\
& \dot{L}_{f-g s c}=\varepsilon_{g s c 1}\left[\frac{d i_{g q}^{*}}{d t}-\frac{1}{L_{f}}\left(-V_{g q}-R_{f} i_{g q}-\right.\right. \\
& \left.\left.\omega_{s} \cdot L_{f} \cdot i_{g d}+V_{g}\right)\right]+\varepsilon_{r s c 2} \cdot\left[\frac{d i_{g d}^{*}}{d t}-\frac{1}{L_{f}}\left(-V_{g d}-\right.\right. \\
& \left.\left.R_{f} i_{g d}+\omega_{s} L_{f} i_{g q}\right)\right]
\end{aligned}
$$

To ensure the stability of the system according to Lyapunov, the derivation of $\mathrm{L}_{\mathrm{f}-\mathrm{gsc}}$ must be negative:
$\dot{L}_{f-r s c}=-C_{g s c 1} \cdot \varepsilon_{g s c 1}^{2}-C_{g s c 2} \cdot \varepsilon_{g s c 2}^{2}$

The virtual command of rotor current is deduced as:

$\frac{d i_{g q}^{*}}{d t}-\frac{1}{L_{f}}\left(-V_{g q}-R_{f} i_{g q}-\omega_{s} \cdot L_{f} \cdot i_{g d}+V_{g}\right)=$

$-C_{g s c 1} \cdot \varepsilon_{g s c 1}$

$\frac{d i_{g d}^{*}}{d t}-\frac{1}{L_{f}}\left(-V_{g d}-R_{f} i_{g d}-\omega_{s} \cdot L_{f} \cdot i_{g q}\right)=$

$-C_{g s c 2} \cdot \varepsilon_{g s c 2}$

So, the expressions of the actual global command $\mathrm{V}_{\mathrm{gd}}$ and $\mathrm{V}_{\mathrm{gq}}$ are defined by:

$V_{g q}=-L_{f} \cdot\left[\frac{d i_{g q}^{*}}{d t}+C_{g s c 1} \cdot \varepsilon_{g s c 1}\right]-R_{f} i_{g q}-$ $\omega_{s} \cdot L_{f} \cdot i_{g d}+V_{g}$

$V_{g d}=-L_{f} \cdot\left[\frac{d i_{g d}^{*}}{d t}+C_{g s c 2} \cdot \varepsilon_{g 2}\right]-R_{f} i_{g d}+$ $\omega_{s} \cdot L_{f} \cdot i_{g q}$

\section{Searching the backstepping constants by the particle swarm optimization algorithm}

\subsection{Particle swarm optimization concept}

The collective intelligence meta-heuristic Particle Swarm Optimization (PSO) algorithm is one of the famous optimization algorithms, which was introduced by Eberhart and Kennedy in 1995. They have proposed it to optimize complicated problems $[23,24]$. The basic principle of PSO was inspired by the social behavior of animals moving in the swarm as bird flocking. Searching food or keeping safe away from enemies, each bird estimates the flying speed based on the personal experience and the information obtained through interaction with other swarm members. Birds or swarm individuals are considered as particles dispersed and moved into multi-directional search-space of the optimization problem to achieve their goal [23]. The mathematical description of the particle swarm optimization algorithm is as follows: in a multidimensional target search space, each particle is seen as a point in a search space and presents a solution for the optimization problem. The population is formed by $\mathrm{N}$ individuals called particles. Each particle coordinates position vector is represented as $\mathrm{X}_{\mathrm{ij}}=\left(\mathrm{x}_{\mathrm{i} 1}, \mathrm{x}_{\mathrm{i} 2}, \ldots, \mathrm{X}_{\mathrm{id}}\right)$, the velocity vector is represented as $\mathrm{V}_{\mathrm{ij}}=\left(\mathrm{v}_{\mathrm{i} 1}, \mathrm{v}_{\mathrm{i} 2}, \ldots, \mathrm{v}_{\mathrm{id}}\right)$ [25]. The 
velocity and the position of each particle are expressed as [23-25]:

$$
\begin{aligned}
& V_{i j}(t+1)=\omega \cdot V_{i j}(t)+C_{1} \cdot r_{1} \cdot\left(P_{\text {best }_{i j}}-\right. \\
& \left.x_{i j}(t)\right)+C_{2} \cdot r_{2} \cdot\left(G_{\text {best }_{j}}-x_{i j}(t)\right) \\
& x_{i j}(t+1)=V_{i j}(t+1)+x_{i j}(t)
\end{aligned}
$$

Where $P_{\text {best }}$ is the best previous position, and $G_{\text {best }}$ is the best value obtained so far by any particle in the neighborhood of that particle. The factors $r_{1}$ and $\mathrm{r}_{2}$ are the random numbers between [0-1]. However, $\mathrm{C}_{1}$ and $\mathrm{C}_{2}$ are the acceleration constants which are defined, respectively [26]:

$$
\begin{aligned}
& C_{1}=C_{1 \text { max }}-\frac{C_{1 \max }-C_{1 \min }}{N_{\text {iter }}} \cdot k \\
& C_{2}=C_{2 \max }+\frac{C_{2 \max }-C_{2 \min }}{N_{\text {iter }}} \cdot k
\end{aligned}
$$

The expression of the inertia weight factor $(\omega)$ is [11]:

$$
\omega=\omega_{\max }-\frac{\omega_{\max }-\omega_{\min }}{N_{\text {iter }}} . k
$$

Where $N_{\text {iter }}$ is the maximum number of iterations and $k$ is the current iteration. The PSO is also characterized by the problem dimension " $\mathrm{d}$ " and the swarm size " $n$ " $[11,23]$.

\subsection{Proposed intelligent control design}

The optimization of Backstepping control parameters, as Cmppt, Crsc1, Crsc2, Cgsc1, Cgsc2, and $\mathrm{Cdc}$, is considered as a challenge. The majority of the Backstepping positive constants are adjusted by manual method. The latter remains a difficult task and takes much time. To deal with this problem, we will apply the PSO algorithm to select the optimal and the proper Backstepping parameters by minimizing the fitness function based on the Integral Absolute Error (IAE), which is defined by [11]:

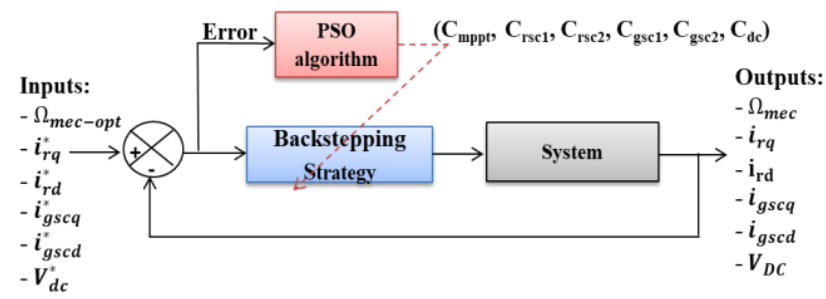

Figure. 2 PSO-backstepping (PSOBS) control design

$$
I A E=\int_{0}^{T_{\operatorname{sim}}}|e(t)| d t
$$

Where $\mathrm{T}_{\text {sim }}$ is the simulation time and $\mathrm{e}(\mathrm{t})$ is the tracking error. The objective function is determined by the weighted sum of errors, as given in Eq. (64). The integral absolute error (IAE) performance criterion is associated with the objective function, as presented in the Eq. (65). By minimizing the fitness function employing the PSO algorithm, the optimal parameters are obtained with fast convergence of the algorithm [27]:

$$
\begin{gathered}
F(t)=\sum_{i=1}^{d} W_{i} \cdot\left|e_{i}(t)\right| \quad ; \text { with } d=6 \\
\operatorname{Obj}(t)=\int_{0}^{T_{\operatorname{sim}}} F(t) d t
\end{gathered}
$$

Where $W_{i}$ are the non-negative weight factors related to the fitness function, which their sum realizes the Eq. (66):

$$
\sum_{i=1}^{d} W_{i}=1 \quad \text { With } i=1 \ldots 6
$$

The adaptive weighted particle swarm optimization is used to measure fitness in this work. Equal weights are taken into account. Similar to the singleobjective situation, each particle's optimization is performed on $\mathrm{Obj}(\mathrm{t})$. The PSO-Backstepping controller is depicted in Fig. 2.

\subsection{Optimization procedure}

The steps of the PSO technique's searching operation are listed below, as mentioned in [28]:

Step 1: Randomly generate an initial population. Step 2: If a prescribed number of iterations are achieved, then the algorithm is stopped.

Step 3: Evaluate the objective function of every particle as defined in Eq. (65) and record the best previous position $(\mathrm{Pi})$ of each particle and the global best position $(\mathrm{Pg})$.

Step 4: For each particle, perform the enhanced velocity updating of formula (58) and the position updating of formula (59).

- Verify the velocity constraint conditions by using the following expressions:

Table 1. The variation band of the constants

\begin{tabular}{lllllll}
\hline & $\mathbf{C}_{\text {mppt }}$ & $\mathbf{C}_{\mathrm{dc}}$ & $\mathbf{C}_{\text {rsc1 }}$ & $\mathbf{C}_{\text {rsc2 }}$ & $\mathbf{C}_{\text {gsc1 }}$ & $\mathbf{C}_{\text {gsc2 }}$ \\
\hline $\boldsymbol{x}_{\max }$ & $1 \mathrm{e}+5$ & $1 \mathrm{e}+5$ & $1 \mathrm{e}+4$ & $1 \mathrm{e}+4$ & $1 \mathrm{e}+7$ & $1 \mathrm{e}+8$ \\
$\boldsymbol{x}_{\text {min }}$ & $1 \mathrm{e}+4$ & $1 \mathrm{e}+2$ & $1 \mathrm{e}+2$ & $1 \mathrm{e}+2$ & $1 \mathrm{e}+5$ & $1 \mathrm{e}+6$ \\
\hline
\end{tabular}


$V_{i}(t+1)=$

$\left\{\begin{array}{clc}V_{\max } & \text { if } & V_{i}(t+1)>V_{\max } \\ V_{i}(t+1) & \text { if } & V_{\min }<V_{i}(t+1)<V_{\max } \\ V_{\min } & \text { if } & V_{i}(t+1)<V_{\min }\end{array}\right.$

- Verify the position constraint conditions of particles as follows:

$x_{i}(t+1)=$

$\left\{\begin{array}{ccc}x_{\max } & \text { if } & x_{i}(t+1)>x_{\max } \\ x_{i}(t+1) & \text { if } & x_{\min }<x_{i}(t+1)<x_{\max } \\ x_{\min } & \text { if } & x_{i}(t+1)<x_{\min }\end{array}\right.$

Step 5: Exit if a termination criterion is met Else go back to step 2.

The boundary constraint conditions of particles are shown in Table 1.

\section{Simulation results, comparisons and robustness test}

To investigate the performance of the Backstepping with particle swarm optimization (PSOBS) method, a wind energy conversion system is built using Matlab/Simulink. The PSOBS is used to generate PWM pulses for controlling bidirectional RSC and GSC converters based on IGBT transistors. The IGBTs' influence on the simulation results, which is the presence of oscillations, may be reduced by using high-frequency switching. The system is simulated under variable wind speed as presented in Fig. 3. The wind speed begins at $9 \mathrm{~m} \mathrm{~s}^{-1}$, but suddenly changes to $11 \mathrm{~m} \mathrm{~s}^{-1}$ at $0.2 \mathrm{~s}$, then quickly evolves to $12.5 \mathrm{~m} \mathrm{~s}^{-1}$ at $0.5 \mathrm{~s}$. Then, at $0.8 \mathrm{~s}$, it drops to $10 \mathrm{~m} \mathrm{~s}^{-1}$ to test the performance and the superiority of the proposed method. To ensure a unity power factor, both the reactive power references $\mathrm{Qg}^{*}$ and $\mathrm{Qs}^{*}$ are set to $0 \mathrm{VAR}$. The system is managed by three strategies that aim to demonstrate the benefits of the suggested method by controlling active and reactive power and maintaining the DC-link voltage constant. The indirect control vector, which is established using typical PI controllers, is the first approach. The pole compensation methodology is used to determine the gains of the PI controllers shown in Table 2. Then, for maximum power point tracking, Conventional Backstepping (BSC) is used and developed for managing components of the wind energy system. The parameters of this technique are adjusted based on the successive test procedure, as shown in Table 3. Finally, the Backstepping controller is utilized in conjunction with the PSO to automatically tune the parameters. The configurations of the particle swarm optimization program are initialized as illustrated in Table 4. The outcomes of the Optimal Backstepping, Conventional Backstepping, and typical PI are compared. The rated mechanical power reference derived by the MPPT algorithm is shown in Fig. 4. The rated output power of $5 \mathrm{MW}$ corresponds to $12.5 \mathrm{~m} \mathrm{~s}^{-1}$, as can be observed plainly. Fig. 5 shows the mechanical speed, which is calculated using three different control strategies: a standard PI controller, a Backstepping controller (BSC), and an optimum Backstepping controller (PSOBS). The generated mechanical power feeds the doubly-fed induction generator (DFIG), which is driven by the rotational speed. In comparison to the PI controller, which has a significant static error value and an unsatisfactory time response, the Optimal Backstepping controller has a good performance for tracking speed reference with a slight signal overshoot on the order of $0.3 \mathrm{~V}$, better time response, and zero static error. Fig. 6 depicts the stator active power following its set point, whereas Fig. 7 compares the three techniques. The time response has been improved from $10(\mathrm{~ms})$ to $1.8(\mathrm{~ms})$, and the static error has been decreased to near zero. However, there are some little ripples in the active power that can be overlooked. The stator reactive power is shown in Fig. 8. Backstepping with particle swarm optimization demonstrates its robustness when the speed reference fluctuates, reducing the time response considerably, especially when the wind profile rapidly changes. The unit power factor is depicted in Fig. 9. Fig. 10 shows the DC-link voltage computed by the conventional PI, the conventional (BSC), and the optimal Backstepping (PSOBS). Remarkably, the PSO approach eliminates the overshoot of the DC link voltage and improves response time. Table 5 summarizes some of these findings. According to the simulation results, PSOBS provides the fastest response time when compared to Conventional BS and standard PI.

\section{Robustness against parameter uncertainties:}

Case 1: Rotor parameter variation of $+30 \%$ : To evaluate the robustness of the proposed method against parameter uncertainties, the resistance and inductance rotor are changed by $+30 \%$ (Rated values+30\%). The effect of parameter modifications on the active power is shown in Figs. 11. 12. The proposed technique outperforms the standard Backstepping and PI controllers in terms of robustness against rotor parameter uncertainty.

Case 2: Filter parameter variation of $+50 \%$ : The value of the filter resistance and inductance is 
growing in rated value $+50 \%$ of rated values to test the robustness of the Backstepping with particle swarm optimization against parameter uncertainties. Fig. 13 shows that changing the filter setting has no discernible effect on the DC-Link voltage computed using the suggested method.

These results show that the optimal Backstepping is more robust than the conventional Backstepping and the classical PI controller in terms of parameter variation of the rotor and filter and that there is no observable effect on the tested quantities when the parameters of the rotor and filter are varied.

The comparison results and robustness test of the three control approaches are shown in this section. Table 6 shows the characteristics of the WECS components employed in the simulation.
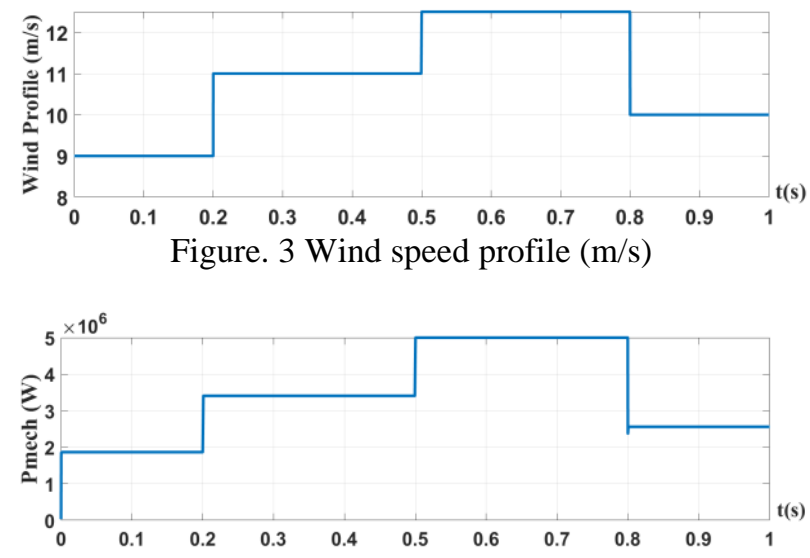

Figure. 4 Mechanical power (W)

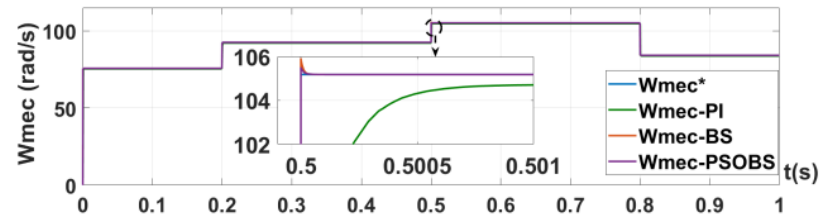

Figure. 5 Mechanical speed computed by the MPPT

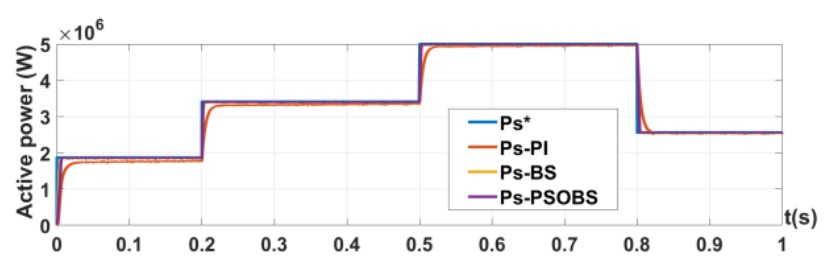

Figure. 6 Stator active power (W)

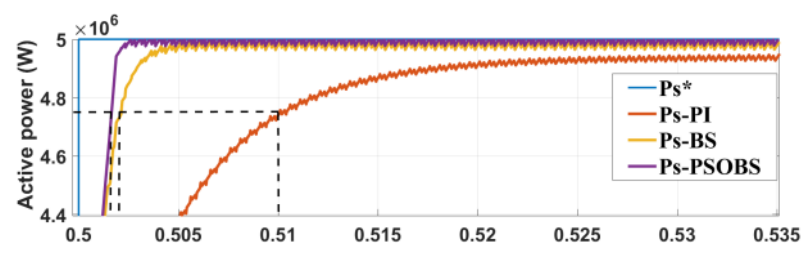

Figure. 7 Stator active power- Zoom

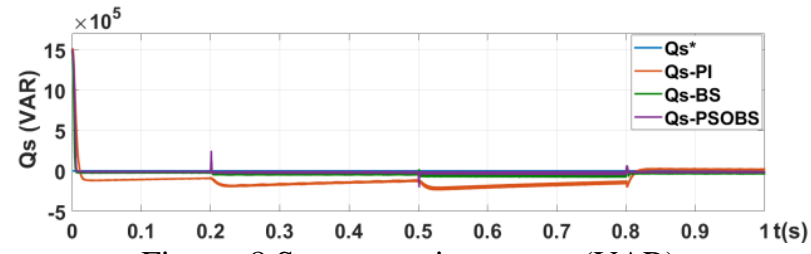

Figure. 8 Stator reactive power (VAR)

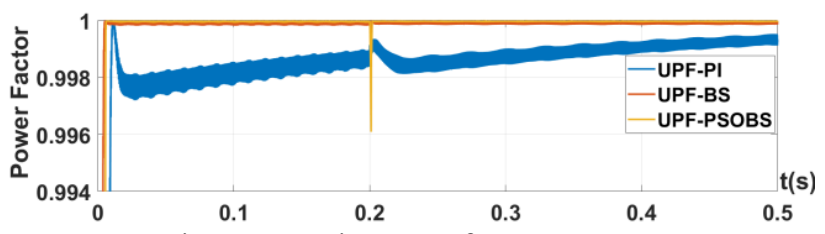

Figure. 9 Unit power factor - Zoom

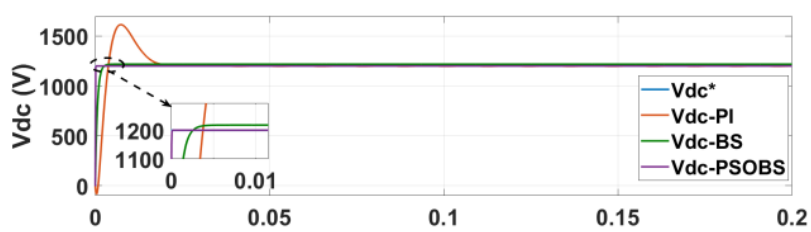

Figure. 10 DC-Link Voltage - Zoom

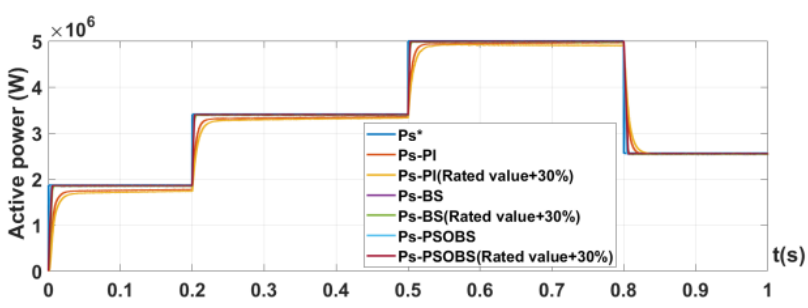

Figure. 11 Active Power for robustness against rotor parameter variation

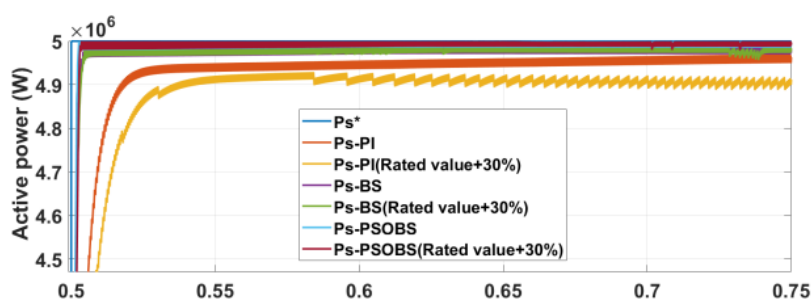

Figure. 12 Active Power for robustness against rotor parameter variation- Zoom in transient regime

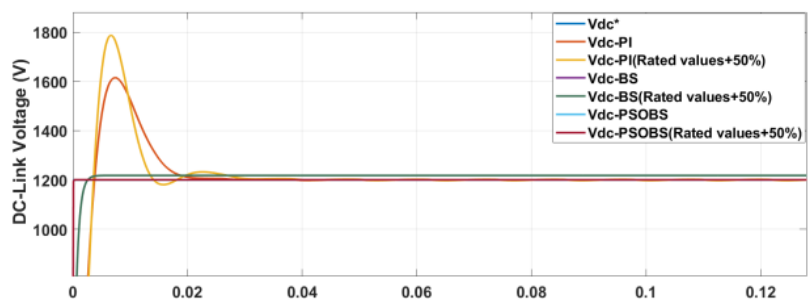

Figure. 13 DC-Link Voltage for robustness against filter parameter variation of $+50 \%$ - Zoom

Table 7. shows a comparison of the suggested technique and various control systems for computing the Backstepping constants that have 
been published in the literature. The response time, error, and overshoot are used to make this comparison. It is evident that the PSO-BS method provides a faster reaction than the other controllers and has a negligible static error with no overshoot.

\section{Conclusion}

The optimal Backstepping controller is realized effectively in this study for piloting the Wind Energy System Conversion (WECS) based on a doubly-fed inductor generator. The rotor is coupled to the stator by back-to-back converters, while the stator is connected directly to the grid. First, utilizing indirect field-oriented control based on traditional PI controllers, the entire wind energy chain is modeled and simulated under changeable wind speed conditions. The traditional Backstepping controller is then set up, with the parameters selected manually. Finally, the suggested optimal Backstepping controller is built using adaptive weights particle swarm optimization to optimize the parameters. The stability of the system is achieved by the Backstepping control, which is based on the Lyapunov function. Simulation results reveal that the proposed strategy has a faster transient response of $82 \%$, a decreased tracking error of $88.75 \%$, and zero overshoot of the DC link voltage, enhanced stability, and superior robustness while compared to other established methods.

\section{Conflicts of interest}

The authors declare that they have no conflict of interest.

\section{Author contributions}

E. Chetouani and Y. Errami wrote the paper and developed the suggested control for the wind power plant system. E. Chetouani used Matlab/Simulink to model the system.

A. Obbadi and S. Sahnoun contributed in the review and correction of the paper's grammar and spelling. The final manuscript was read and approved by all authors.

\section{Appendix}

Table 2. Proportional and integral (PI) gains for vector control

\begin{tabular}{llllll}
\hline $\mathbf{K} \mathbf{p}_{\text {dc }}$ & $\mathbf{K i}_{\mathbf{d c}}$ & $\mathbf{K}_{\mathbf{r s c} \mathbf{1} / \mathbf{2}}$ & $\mathbf{K i}_{\mathbf{r s c 1} / \mathbf{2}}$ & $\mathbf{K}_{\mathbf{g s c} \mathbf{1} \mathbf{2}}$ & $\mathbf{K i}_{\mathbf{g s c 1} \mathbf{2}}$ \\
\hline 1.848 & 396 & 0.1446 & 0.2376 & 200 & $5 \mathrm{e}+4$ \\
\hline
\end{tabular}

Table 3. Backstepping control parameters

\begin{tabular}{lll}
\hline BS Constants & Conventional BS & PSO-BS \\
\hline $\mathbf{C}_{\mathbf{m p p t}}$ & $1 \mathrm{e}+5$ & $8 \mathrm{e}+4$ \\
$\mathbf{C}_{\mathbf{d c}}$ & $3 \mathrm{e}+3$ & $1 \mathrm{e}+5$ \\
$\mathbf{C}_{\mathbf{r s c 1}}$ & $1 \mathrm{e}+3$ & $3 \mathrm{e}+3$ \\
$\mathbf{C}_{\mathbf{r s c} 2}$ & $1 \mathrm{e}+3$ & $2.7929 \mathrm{e}+3$ \\
$\mathbf{C}_{\text {gsc1 }}$ & $1 \mathrm{e}+6$ & $1 \mathrm{e}+7$ \\
$\mathbf{C}_{\mathbf{g s c} 2}$ & $1 \mathrm{e}+7$ & $2.0636 \mathrm{e}+7$ \\
\hline
\end{tabular}

Table 4. Particle swarm optimization code parameters

\begin{tabular}{cc}
\hline Parameters & Value \\
\hline Population size & 15 \\
Number of parameters & 6 \\
Number of iterations & 20 \\
$\mathbf{W}_{\max }$ & 0.9 \\
$\mathbf{W}_{\min }$ & 0.4 \\
$\mathbf{C}_{1 \max }=\mathbf{C}_{2 \max }$ & 2 \\
$\mathbf{C}_{1 \text { min }}=\mathbf{C}_{2 \text { min }}$ & 0.1 \\
\hline
\end{tabular}

Table 5. Summary of the obtained results Performance of the system

\begin{tabular}{ccccccccccc}
\hline & \multicolumn{3}{c}{$\begin{array}{c}\text { Response time } \\
(\mathbf{m s})\end{array}$} & \multicolumn{3}{c}{ Static error } & \multicolumn{3}{c}{$\begin{array}{c}\text { Overshoot } \\
(\text { V) }\end{array}$} \\
& PI & Bsc & Pso- & PI & Bsc & Pso-Bs & PI & Bsc & Pso \\
& & & Bs & & & & & & - Bs \\
Ps & 10 & 2.1 & 1.8 & 0.08 & 0.04 & 0.009 & - & - & - \\
$V_{\text {dc }}$ & 16 & 1.7 & 0,53 & 0 & 18 & 0 & 414 & 18 & 0 \\
\hline
\end{tabular}

Table 6. Set of parameters used in the simulation

\begin{tabular}{|c|c|c|c|}
\hline \multirow[t]{3}{*}{ Turbine } & Radius of blade & $\mathbf{R}$ & $51,583 \mathrm{~m}$ \\
\hline & Coeff. of multiplier & $\mathrm{G}_{\mathrm{B}}$ & 47,23 \\
\hline & $\begin{array}{l}\text { Total moment of } \\
\text { inertia }\end{array}$ & $\mathrm{J}_{\text {tot }}$ & $1000 \mathrm{~kg} \cdot \mathrm{m}^{2}$ \\
\hline \multirow[t]{6}{*}{ DFIG } & DFIG rated power & Ps & $5 \mathrm{MW}$ \\
\hline & Stator inductance & Ls & $1,2721 \mathrm{mH}$ \\
\hline & Rotor resistance & $\mathrm{Rr}$ & $1,446 \mathrm{~m} \Omega$ \\
\hline & Rotor inductance & $\mathrm{Lr}$ & $1,1194 \mathrm{mH}$ \\
\hline & Mutual inductance & M & $0,55187 \mathrm{mH}$ \\
\hline & $\begin{array}{l}\text { Stator line to line } \\
\text { voltage }\end{array}$ & Vs & $950 \mathrm{~V}$ \\
\hline \multirow[t]{2}{*}{ Capacity } & DC-Link capacitor & $\mathrm{C}$ & $4400 \mu \mathrm{F}$ \\
\hline & DC-Link Voltage ref. & $\mathrm{V}_{\mathrm{dc}} *$ & $1200 \mathrm{~V}$ \\
\hline Filter & Filter's resistor & $\mathrm{R}_{\mathrm{f}}$ & $20 \Omega$ \\
\hline $\mathbf{R L}$ & Filter's inductance & $\mathrm{L}_{\mathrm{f}}$ & $0,08 \mathrm{H}$ \\
\hline
\end{tabular}


Table 7. A comparison of our findings with those of other researchers

\begin{tabular}{lcccc}
\hline Ref. Paper & Method & $\begin{array}{c}\text { Response } \\
\text { time }(\mathbf{m s})\end{array}$ & $\begin{array}{l}\text { Error } \\
(\%)\end{array}$ & $\begin{array}{l}\text { Over- } \\
\text { shoot(\%) }\end{array}$ \\
\hline $\begin{array}{l}\text { T.Aounallah } \\
(\mathbf{2 0 1 8})[29]\end{array}$ & $\begin{array}{c}\text { Fuzzy- } \\
\text { logic } \\
\text { BS }\end{array}$ & $\approx 150$ & - & $150 \%$ \\
$\begin{array}{l}\text { B.Bosoufi } \\
\mathbf{( 2 0 2 1 )}[30]\end{array}$ & $\begin{array}{c}\text { RTO- } \\
\text { BS }\end{array}$ & 55 & 1.05 & Null \\
$\begin{array}{l}\text { Our } \\
\text { suggested } \\
\text { technique }\end{array}$ & PSO-BS & 1.8 & 0.9 & Null \\
\hline
\end{tabular}

\section{References}

[1] T. K. Roy, M. A. Mahmud, and A. M. T. Oo, "Nonlinear Backstepping Controller Design for Improving Fault Ride Through Capabilities of DFIG-Based Wind Farms", In: Proc. of IEEE Power \& Energy Society General Meeting (PESGM), Portland, OR USA, pp. 1-5, 2018.

[2] A. Khaled, A. Y. Abdelaziz, H. M. E. Helw, and M. Ezzat, "Protecting Doubly Fed Induction Generator's Converter Using A Filter Based TCR", In: Proc. of IEEE International Conf. on Environment and Electrical Engineering and IEEE Industrial and Commercial Power Systems Europe, Spain, pp. 1-4, 2020.

[3] Y. Iherdane, C. El Bekkali, M. El Ghamrasni, S. Mensou, and B. Bossoufi, "Improved wind system using non-linear power control", Indonesian Journal of Electrical Engineering and Computer Science, Vol. 14, No. 3, pp. 1148-1158, 2019.

[4] J.T. Jose, and A. B. Chattopadhyay, "Mathematical Formulation of Feedback Linearizing Control of Doubly Fed Induction Generator Including Magnetic Saturation Effects", Hindawi Mathematical Problems in Engineering, Vol. 2020, pp. 1-10, 2020.

[5] P. Li, L. Xiong, F. Wu, M. Ma, and J. Wang, "Sliding mode controller based on feedback linearization for damping of sub-synchronous control interaction in DFIG-based wind power plants", International Journal of Electrical Power \& Energy Systems, Vol. 107, pp. 239250, 2019.

[6] M. Elmahfoud, B. Bossoufi, and M. taoussi, "Comparative Study between Backstepping Adaptive and Field Oriented Controls for Doubly Fed Induction Motor", European Journal of Electrical Engineering, vol. 22, No. 3, pp. 209-221, 2020.

[7] M. E. Ghamrasni, H. Mahmoudi, A. Lagrioui, and B. Bossoufi, "Comparison of Power
Control Methods of DFIG for Wind Turbines", In: Proc. of 6th International Renewable and Sustainable Energy Conf. (IRSEC), Rabat, Morocco, pp. 1-8, 2018.

[8] Y. Djeriri, "Lyapunov-Based Robust Power Controllers for a Doubly Fed Induction Generator", Iranian Journal of Electrical and Electronic Engineering, Vol. 16, No. 4, pp. 551-558, 2020.

[9] M. Benakcha, L. Benalia, D. E. Tourqui, and A. Benakcha, "Backstepping Control of Dual Stator Induction Generator used in Wind Energy Conversion System", Int. Journal of Renewable Energy Research, Vol. 8, No. 1, pp. 384-395, 2018.

[10] M. Nadour, A. Essadki, and T. Nasser, "Comparative Analysis between PI \& Backstepping Control Strategies of DFIG Driven by Wind Turbine", International Journal of Renewable Energy Research, Vol. 7, No. 3, pp. 1307-1316, 2017.

[11] M. A. M. Basri, K. A. Danapalasingam, and A. R. Husain, "Design and optimization of backstepping controller for an underactuated autonomous quadrotor unmanned aerial vehicle", Transactions of Famena, Vol. 38, No. 3, pp. 27-44, 2014.

[12] H. Salmi, A. Badri, M. Zegrari, A. Sahel, and A. Baghdad, "PSO-Backstepping controller of a grid connected DFIG based wind turbine", Int. Journal of Electrical and Computer Engineering (IJECE), Vol. 10, No. 1, pp. 856867, 2020.

[13] A.Mechter, K. Kemih, and M. Ghanes, "Backstepping control of a wind turbine for low wind speeds", Nonlinear Dynamics, Vol. 84, No. 4, pp. 2435-2445, 2016.

[14] S. Labdai, B. Hemici, L. Nezli, N. Bounar, A. Boulkroune, and L. Chrifi-Alaoui, "Robust Control based on Backstepping and adaptive neural network for the DFIG based WECS," In: Proc. of 2019 Int. Conf. Control. Autom. Diagnosis (ICCAD), Grenoble, France, pp. 1-6, 2019.

[15] O. Ben Belghith, L. Sbita, and F. Bettaher, "MPPT Design Using PSO Technique for Photovoltaic System Control Comparing to Fuzzy Logic and P\&O Controllers", Energy and Power Engineering, Vol. 8, No. 11, pp. 349-366, 2016.

[16] M. E. Barios Aguilar, D. Vinicius Coury, R. Reginatto, and R. M. Monaro, "Multi-objective PSO applied to PI control of DFIG wind turbine under electrical fault conditions", 
Electric Power Systems Research, Vol. 180, No. 2019, p. 106081, 2020.

[17] Y. Errami, A. Obbadi, S. Sahnoun, M. Benhmida, M. Ouassaid, and M. Maaroufi, "Design of a nonlinear backstepping control strategy of grid interconnected wind power system based PMSG", In: Proc. of AIP Conference Proceedings, Beirut, Lebanon, p. 030053, 2016.

[18] M. Bouderbala, B. Bossoufi, A. Lagrioui, M. Taoussi, H. Alami Aroussi,and Y. Ihedrane, "Direct and indirect vector control of a doubly fed induction generator based in a wind energy conversion system", Int. J. of Electrical and Computer Engineering, Vol. 9, No. 3, pp. 15311540, 2018.

[19] A. Oumar, R. Chakib, M. Labbadi, and M. Cherkaoui, "Robust nonlinear controller of the speed for double star induction machine in the presence of a sensor fault", International Journal of Intelligent Engineering and Systems, Vol. 13, No. 3, pp. 124-133, 2020.

[20] A. Dahbi, N. Nait-Said, and M. Nait-Said, "A novel combined MPPT-pitch angle control for wide range variable speed wind turbine based on neural network", International Journal of Hydrogen Energy, Vol. 41, No. 22, pp. 94279442, 2016.

[21] Z. Sheng, E. Yong, Y. Zhou, and W. Q. Qian, "Dynamic backstepping control for purefeedback non-linear systems", IMA Journal of Mathematical Control and Information, Vol. 37, No. 2, pp. 670-693, 2020.

[22] C. X. Chen, Y. X. Xie, and Y. H. Lan, "Backstepping Control of Speed Sensorless Permanent Magnet Synchronous Motor Based on Slide Model Observer", Inter. Journal of Automation and Computing, Vol. 12, No. 2, pp. 149-155, 2015.

[23] N. El Gmili, M. Mjahed, A. El Kari, and H. Ayad, "Particle swarm optimization based proportional-derivative parameters for unmanned tilt-rotor flight control and trajectory tracking", AUTOMATIKA, Vol. 61, No. 2, pp. 189-206, 2020.

[24] M. Chouket, A. Abdelkafi, and L.Krichen, "Wind Turbine PI Controller's Optimization Using PSO Algorithm", In: Proc. of 15th Int. Multi-Conference on Systems, Signals \& Devices (SSD), Hammamet, Tunis, pp. 12871292, 2018.

[25] B. Zahra, H. Salhi, and A. Mellit, "Wind turbine performance enhancement by control of pitch angle using PID controller and particle swarm optimization", In: Proc. of 5th Inter.
Conf. on Electrical Engineering - Boumerdes

(ICEE-B), Boumerdes, algeria, pp. 1-5, 2017.

[26] R. Laina, F. Ez. Lamzouri, E. Boufounas, A. E. Amrani, and I. Boumhidi, "Intelligent control of a DFIG wind turbine using a PSO evolutionary algorithm", In: Proc. of the First International Conference on Intelligent Computing in Data Sciences, Meknes, Morocco, pp. 471-480, 2018.

[27] Z. Chen, Z. Lin, C. Yue, and Y. Li, "Particle Swarm Optimized Command Filtered Backstepping Control for an Active Magnetic Bearing System", In: Proc. of IEEE International Conference on Information and Automation (ICIA), Wuyishan, China, pp. 155160, 2018.

[28] A. Vincent and R. Nersisson, "Particle swarm optimization based PID controller tuning for level control of two tank system", In: Proc. of 14th International Conference on Science, Engineering and Technology, Vellore, India, pp. 1-7, 2017.

[29] T. Aounallah, N. Essounbouli, A. Hamzaoui, and F. Bouchafaa, "Algorithm on fuzzy adaptive backstepping control of fractional order for doubly-fed induction generators", IET Renew. Power Gener., Vol. 12, No. 8, pp. 962967, 2018,

[30] B. Bossoufi, M. Karim, M. Taoussi, H. A. Aroussi, M. Bouderbala, O. Deblecker, S. Motahhir, A. Nayyar, and M. Alsain, "Rooted tree optimization for the backstepping power control of a doubly fed induction generator wind turbine: Dspace implementation", IEEE Access, Vol. 9, pp. 26512-26522, 2021. 